\title{
lloprost to improve surfactant function in porcine pulmonary grafts stored for twenty-four hours in low-potassium dextran solution
}

\author{
Bernhard Gohrbandt, MD \\ Sebastian P. Sommer, MD ${ }^{a}$ \\ Stefan Fischer, MD, MSc ${ }^{\text {a }}$ \\ Jens M. Hohlfeld, MD ${ }^{\mathrm{b}}$ \\ Gregor Warnecke, MD \\ Axel Haverich, MD ${ }^{\mathrm{a}}$ \\ Martin Strueber, MD
}

From the Hannover Thoracic Transplant Program, Division of Thoracic and Cardiovascular Surgery, ${ }^{\mathrm{a}}$ and the Department of Respiratory Medicine, ${ }^{\mathrm{b}}$ Hannover Medical School, Hannover, Germany.

Received for publication Dec 18, 2003; revisions received March 5, 2004; accepted for publication April 6, 2004

Address for reprints: Martin Strueber, MD, Director, Hannover Thoracic Transplant Program, Division of Cardiothoracic and Vascular Surgery, Hannover Medical School, Carl-Neuberg-Strasse 1, 30623 Hannover,Germany (E-mail: strueber@thg. mh-hannover.de).

J Thorac Cardiovasc Surg 2005;129:80-6 $0022-5223 / \$ 30.00$

Copyright (C) 2005 by The American Association for Thoracic Surgery

doi:10.1016/j.jtcvs.2004.04.040
Objectives: The optimal strategy for pulmonary graft preservation remains elusive. Experimental work and initial clinical experience support low-potassium dextran solutions as lung perfusates. We have previously shown a protective effect of prostaglandin $E_{1}$ on ischemia-reperfusion injury in lung transplantation by a shift from proinflammatory to anti-inflammatory cytokines in a rat lung transplantation model. In this study, we tested the hypothesis that the addition of a prostacyclin analog (iloprost) to low-potassium dextran might lead to improved surfactant and ultimately graft function.

Methods: In a randomized, blinded study with a porcine left single-lung transplantation model, donor lungs were flushed with $1 \mathrm{~L}$ of either low-potassium dextran solution or low-potassium dextran solution modified by the addition of $250 \mu \mathrm{g}$ iloprost ( $n=6$ in each group). Grafts were stored at $4^{\circ} \mathrm{C}$ for 24 hours. After transplantation, the right bronchus and pulmonary artery were clamped, and the animals remained dependent on the graft. Posttransplantation graft function was assessed throughout a 7-hour observation period by measuring oxygenation (30minute intervals), different pulmonary and systemic hemodynamic parameters, and wet/dry lung weight ratios. Bronchoalveolar lavage fluid was obtained before and 2 hours after reperfusion. Surfactant function was measured from bronchoalveolar lavage fluid with a pulsating bubble surfactometer. Neutrophil sequestration was assessed by a myeloperoxidase assay performed on lung tissue specimens taken at the end of the observation period.

Results: Pulmonary vascular resistance remained lower in the iloprost group than in the control group $(P<.05)$. Tissue water content after 7 hours of reperfusion remained lower in the iloprost group $(P<.05)$. In addition, significantly reduced myeloperoxidase tissue activity was observed in the iloprost group $(P<.05)$. Although there was no difference in degradation of surface active surfactant large aggregates to small aggregates, the surface tension measured at minimal bubble diameter was lower in the iloprost group $(P<.05)$.

Conclusions: Modification of low-potassium dextran solution with the prostacyclin analog iloprost resulted in a significant amelioration of ischemia-reperfusion injury and improved preservation of surfactant function in transplanted lungs. This intriguing approach merits further evaluation with respect to the mechanisms involved and, ultimately, potential introduction into clinical lung transplantation. 
I schemia-reperfusion (IR) injury is a major cause of life-threatening primary graft dysfunction in approximately $10 \%$ to $20 \%$ of patients after lung transplantation. ${ }^{1}$ In addition, obliterative bronchiolitis is increasingly believed to be the result of abnormal healing processes triggered by IR injury and immunologic responses against the graft. This theory is supported by the fact that major histocompatibility complex class II molecules are upregulated in posttransplantation pulmonary IR injury. ${ }^{2,3}$ Crocetti and coworkers ${ }^{4}$ have described a possible relationship between the severity of posttransplantation lung IR injury and the development of obliterative bronchiolitis.

Many strategies of lung procurement have been developed and applied worldwide, with no concrete consensus regarding which is the most effective. ${ }^{5}$ Safe graft ischemic times are generally considered to be around 6 to 8 hours, irrespective of which technique is used, suggesting that none is superior to the others for short-term preservation of good quality donor organs. Low-potassium dextran solution (LPD) has been evaluated in experimental studies thoroughly during the past decade ${ }^{6-8}$ with superior results and has been successfully introduced into clinical lung transplantation by us and others. ${ }^{9,10}$ We strive continually for further improvement. The ability to preserve the more marginal donor lungs with confidence could potentially increase the pool of suitable donor organs.

Members of the prostanoid family have been shown to be beneficial in improving graft function when added to preservation solutions such as Euro-Collins or University of Wisconsin. ${ }^{11,12}$ Euro-Collins is an intracellular-type preservation solution, with high potassium concentrations that may cause vasoconstriction. The beneficial effect of iloprost therefore previously was attributed to its vasodilatory property, which probably leads to a better distribution of preservation solution throughout all parts of the lung graft. In addition, prostanoids may promote pulmonary protection by stimulating cyclic $3^{\prime}, 5^{\prime}$-adenosine monophosphate (cAMP)dependent protein kinase during cold ischemia; cAMPdependent protein kinase has been shown to reduce endothelial permeability and to prevent neutrophil adhesion and platelet aggregation. ${ }^{13}$ We have recently shown in a smallanimal model that prostaglandin (PG) significantly improves lung function relative to the already superior lung preservation associated with LPD by a shift from proinflammatory to anti-inflammatory cytokines. ${ }^{14}$ The protective effect was achievable either by administration of the drug to the flush solution or by continuous intravenous administration throughout the reperfusion period. The protective effect of $\mathrm{PGE}_{1}$ was partially attributed to its vasodilatory property, which reduces shear stress injury in lung grafts. ${ }^{15}$ However, other vasodilatory agents did not have similar effects when administered continuously during the reperfusion period after lung ischemia. ${ }^{16}$ Prostanoids and their derivatives therefore clearly have additional cytoprotective benefits on lung grafts through mechanisms that remain largely unknown.

The primary purpose of this study was to determine whether iloprost, when administered in the preservation solution, improves lung function and ameliorates IR injury in the transplanted lung in a preclinical, large-animal, single-lung transplantation model. Secondarily we sought to determine whether such improvement was associated with improved preservation of surfactant function in the graft after the entire lung preservation, transplantation, and reperfusion process.

\section{Material and Methods \\ Experimental Groups}

Pigs were randomly divided into two groups of 6 animals each. In the iloprost group, lungs were preserved with LPD (Perfadex; Vitrolife, Göteborg, Sweden) plus $250 \mu \mathrm{g} / \mathrm{L}$ of iloprost (Ilomedin; Schering AG, Berlin, Germany) with the antegrade flush perfusion technique. In the control group, lungs were flushed with LPD only with the same flushing technique.

\section{Surgical Preparation}

Donor animal procedure. Female pigs (25-30 kg) were anesthetized with sodium pentobarbital $(10 \mathrm{mg} / \mathrm{kg})$ and fentanyl $(1$ $\mathrm{mg} / \mathrm{kg}$ followed by a fentanyl infusion of $\left.1 \mathrm{mg} \cdot \mathrm{kg}^{-1} \cdot \mathrm{h}^{-1}\right)$. The animals were intubated and ventilated with $100 \%$ oxygen (inspiratory/expiratory ratio of $1: 1$, positive end-expiratory pressure of 5 $\mathrm{mm} \mathrm{Hg}$ ) in pressure-controlled mode with a maximum airway pressure of $20 \mathrm{~mm} \mathrm{Hg}$ and a ventilation rate of 10 breaths/min. A median sternotomy was performed, and the pericardium was cut open. A catheter to infuse preservation solution was inserted into the main pulmonary artery. Heparin $(3 \mathrm{mg} / \mathrm{kg})$ was administered intravenously. Cardiac arrest was induced by clamping of the aorta, and cardioplegic solution was infused into the aortic root. The venae cavae were clamped. Thereafter the left atrial auricle was incised, and flush perfusion of the pulmonary artery was induced. In 10 minutes $1000 \mathrm{~mL}$ of LPD or LPD plus iloprost was administered at a temperature of $8^{\circ} \mathrm{C}$. Ventilation of the lungs was maintained throughout the entire flushing procedure. The heart and lungs were excised en bloc. Care was taken to clamp the main left bronchus, leaving the lung in a mildly inflated state. The left lung was isolated from the heart-lung-block with a generous atrial cuff and full lengths of both pulmonary arteries and main bronchus. The lung was stored at $4^{\circ} \mathrm{C}$ in LPD for 24 hours.

Transplantation procedure. Female pigs $(25-30 \mathrm{~kg})$ were anesthetized with sodium pentobarbital $(10 \mathrm{mg} / \mathrm{kg})$ and fentanyl (1 $\mathrm{mg} / \mathrm{kg}$ followed by a fentanyl infusion of $\left.1 \mathrm{mg} \cdot \mathrm{kg}^{-1} \cdot \mathrm{h}^{-1}\right)$. The animals were intubated and ventilated with $50 \%$ oxygen (inspiratory/expiratory ratio of $1: 1$, positive end-expiratory pressure of 5 $\mathrm{mm} \mathrm{Hg}$ ) in pressure-controlled mode with a maximum airway pressure of $20 \mathrm{~mm} \mathrm{Hg}$ and a ventilation rate of 10 breaths $/ \mathrm{min}$. A Swan-Ganz catheter (Baxter Healthcare Corporation CardioVascular Group, Irvine, Calif) and a catheter to monitor arterial pressure were placed into the right internal jugular vein and carotid artery, respectively. A further catheter for monitoring extravascu- 
lar lung water and intrathoracic total blood volume was inserted into the right femoral artery. A left thoracotomy in the fifth intercostal space was performed, and the pericardium was opened. The left pulmonary artery, the tracheal bifurcation, and the pulmonary veins were dissected. Umbilical tapes were applied to the right and left pulmonary arteries and the right main bronchus. A heparin dose of $300 \mathrm{IE} / \mathrm{kg}$ was administered intravenously. After clamping of the left main bronchus and the left pulmonary artery, the left pulmonary veins were ligated. Pneumonectomy of the left lung was performed. A clamp was placed to the left atrium to close the left pulmonary veins. The upper and lower pulmonary veins were incised with the atrial tissue between those to open an atrial cuff. Ventilation was continued, and the donor lung was implanted starting with a bronchial end-to-end anastomosis with 4-0 polypropylene running suture. Anastomosis of the left atrial cuff of the donor lung with the recipient's left atrial cuff was performed, followed by completion of the left pulmonary artery end-to-end anastomosis with 4-0 polypropylene running sutures. Immediately before reperfusion, the graft vasculature was deaired by retrograde perfusion. The pulmonary artery was declamped, and the graft was ventilated. After 15 minutes of reperfusion, the right pulmonary artery and main right bronchus were clamped. Experiments were terminated by means of a pentobarbital overdose after 7 hours of reperfusion.

\section{Measurements of Lung Function, Extravascular Lung Water, and Total Intrathoracic Blood Volume}

In all experiments, atrial, systemic arterial, and pulmonary arterial pressures were recorded on-line. Dynamic lung compliance was monitored continuously with a modified ventilator (Dräger, Lübeck, Germany). Arterial blood gas analysis was performed after placement of catheters and every 30 minutes during the reperfusion period. At these intervals, pulmonary vascular resistance (PVR) was calculated after measurement of cardiac output by means of the transfemoral thermodilution catheter, which was connected to the cardiac index (CI) computer (PICCO; Pulsion Medical Systems AG, Munich, Germany). After calibration by injection of cold $0.9 \%$ saline solution into the jugular vein, the system calculated CI online by pressure curve analysis. ${ }^{17} \mathrm{By}$ means of the same thermal bolus injection that was distributed into intravascular blood volume and extravascular lung water, the extravascular lung water index (arithmetic value divided by body weight in kilograms) was computed. ${ }^{18}$ For wet/dry ratios, specimens were taken at the same site of pulmonary grafts to achieve most comparable conditions.

\section{Surfactant Analysis}

Bronchoalveolar lavage fluid was obtained with $100 \mathrm{~mL}$ of $0.9 \%$ saline solution from the right lower lobe in each donor for baseline measurements. A second bronchoalveolar lavage, of the left lower lobe, was performed after 2 hours of reperfusion. A differential cell count was carried out to determine the number of polymorphonuclear leukocytes as a percentage of the total cell count. The lavage fluid was immediately centrifuged at $150 \mathrm{~g}$, and the cell-free supernatant was frozen at $-80^{\circ} \mathrm{C}$. Pellet and supernatant were separated at $48,000 \mathrm{~g}$ for 60 minutes. Protein and phospholipid contents were determined. Phospholipids in the small aggregate (SA)-containing supernatant and in the large aggregate (LA)containing pellet were determined by phosphorus analysis, and these contents were expressed in the SA/LA weight ratio. The surfactant pellet was resuspended in saline solution supplemented with calcium chloride $(1.5 \mathrm{mmol} / \mathrm{L})$. Surfactant function was determined with a pulsating bubble surfactometer (Electronetics Inc, Buffalo, NY). According to the technique described by Enhorning, ${ }^{19} 40 \mathrm{~mL}$ of LA suspension, adjusted to a phospholipid concentration of $1 \mathrm{mg} / \mathrm{mL}$, was analyzed. The surface tension at minimal bubble size $\left(\gamma_{\min }\right)$ was obtained after 5 minutes of bubble pulsation at a rate of 20 cycles/min and a temperature of $37^{\circ} \mathrm{C}$. Before bubble pulsation was started, adsorption was determined as surface tension 10 seconds after formation of a bubble. All analog data were digitized and recorded on a personal computer.

\section{Myeloperoxidase Activity Assay}

Lung tissue was assayed for myeloperoxidase (MPO) activity, an index of polymorphonuclear neutrophil sequestration, according to the method of Suzuki and coworkers. ${ }^{20}$ MPO activity was assessed at $37^{\circ} \mathrm{C}$ by monitoring the change in absorbance at $655 \mathrm{~nm}$ through a 3-minute period in a COBAS FARA II centrifugal analyzer (Roche Diagnostics Corporation, Laboratory Systems, Indianapolis, Ind). The reaction mixture contained $16-\mathrm{mmol} / \mathrm{L} 3,3^{\prime}, 5,5^{\prime}$ tetramethylbenzidine dissolved in $\mathrm{N}, \mathrm{N}$-dimethlyformamide in $0.22-\mathrm{mol} / \mathrm{L}$ phosphate buffer that contained $0.11-\mathrm{mol} / \mathrm{L}$ sodium chloride at $\mathrm{pH}$ 5.4. The reaction was initiated by the addition of 3-mmol/L hydrogen peroxide. One unit of activity was defined as a change of 1 unit in absorbance per minute at $37^{\circ} \mathrm{C}$. Protein contents of samples was determined by the bicinchoninic acid protein assay system (Pierce Chemical Company, Rockford, Ill). MPO activity is expressed as units per milligram of protein.

\section{Animal Care}

All animal received human care in compliance with the "Principles of Laboratory Animal Care" formulated by the National Society for Medical Research and the "Guide for the Care and Use of Laboratory Animals" (http://www.nap.edu/catalog/5140.html).

\section{Statistical Analysis}

All data are expressed as mean \pm SD. Continuous data were analyzed by repeated measures analysis of variance. For data without repeated measurement, analysis of variance was applied. Data obtained from the 2 animals that died during the observation period were included in statistical analyses up to the point at which death occurred. All data were analyzed with SPSS software (SPSS for MS Windows, version 11.5; SPSS Inc, Chicago, Ill).

\section{Results}

Donor and recipient pigs were matched for size in each study group. The mean $\mathrm{PaO}_{2}$ levels in arterial blood in donor animals in each group were not different. Two of the 6 recipient animals in the control group died during the reperfusion period from right heart failure at 2.5 and 4 hours after initiation of reperfusion. All animals in the iloprost group survived for the entire observation period.

\section{Iloprost and Posttransplantation Lung IR Injury}

After completion of the 7 hours of reperfusion, a mild trend toward higher $\mathrm{PaO}_{2}$ levels was seen in the iloprost group 


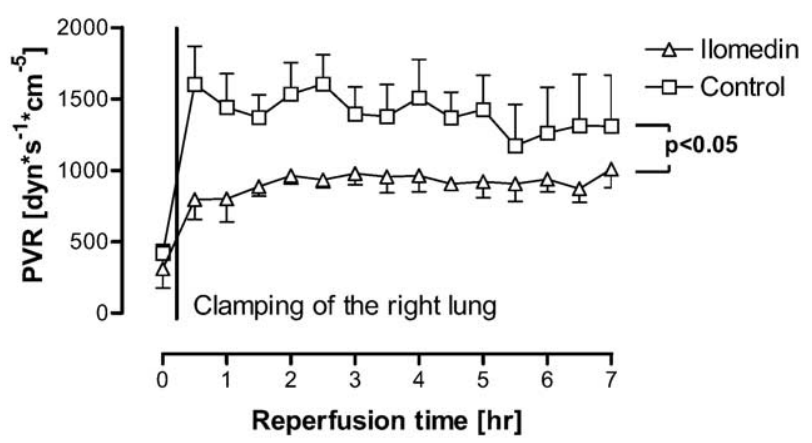

Figure 1. Changes in PVR with time in iloprost (llomedin) and control groups throughout 7-hour reperfusion period.

$(201 \pm 86 \mathrm{~mm} \mathrm{Hg})$ relative to the control group $(169 \pm 92$ $\mathrm{mm} \mathrm{Hg}$ ). However, this trend did not reach statistical significance. PVR was significantly lower in the iloprost group with time throughout the observation period than in the control cohort $(P<.05)$. Figure 1 illustrates the changes in PVR with time in both groups throughout the 7-hour reperfusion period. Pulmonary arterial pressure, CI, and extravascular lung water content were all not statistically different between groups; however, trends toward lower pulmonary arterial pressures $(P=.1)$, increased CI $(P=$ $.09)$, and less extravascular lung water content $(P=.06)$ were observed in the iloprost group. In addition, wet/dry lung weight ratios were significantly lower at the end of the reperfusion period in the iloprost group than in the control group $(P<.05)$. Figure 2 shows wet/dry weight ratios at the end of the reperfusion period.

Neutrophil sequestration in lung grafts was examined by determination of MPO activity in lung tissue. As depicted in Figure 3, MPO activity was significantly lower at the end of the reperfusion period in the iloprost group than in the control group $(P<.05)$.

\section{Effect of Iloprost on Surfactant Function and Alveolar Surface Tension}

Surfactant function was determined with a pulsating bubble surfactometer. The analysis of surfactant function revealed low minimal surface tension in donor lungs, considered as baseline measurements for healthy lungs. After 2 hours of reperfusion, a significant increase in surface tension $(P<$ .05 ) was seen in the iloprost group, as shown in Figure 4. Although significantly different from baseline, values of $\gamma_{\min }$ of $3 \mathrm{mN} / \mathrm{m}$ indicate a good preservation of surfactant function by iloprost. Lungs preserved with LPD without iloprost (control) reached higher values of $\gamma_{\min }(6 \pm 2$ $\mathrm{mN} / \mathrm{m}$ ) than seen the iloprost group, indicating a slight to moderate surfactant dysfunction. The SA/LA ratio was at a low level in right donor lungs (baseline measurements) before graft retrieval (Figure 5). After 2 hours of reperfusion, a tremendous increase of SA/LA-ratio, suggesting

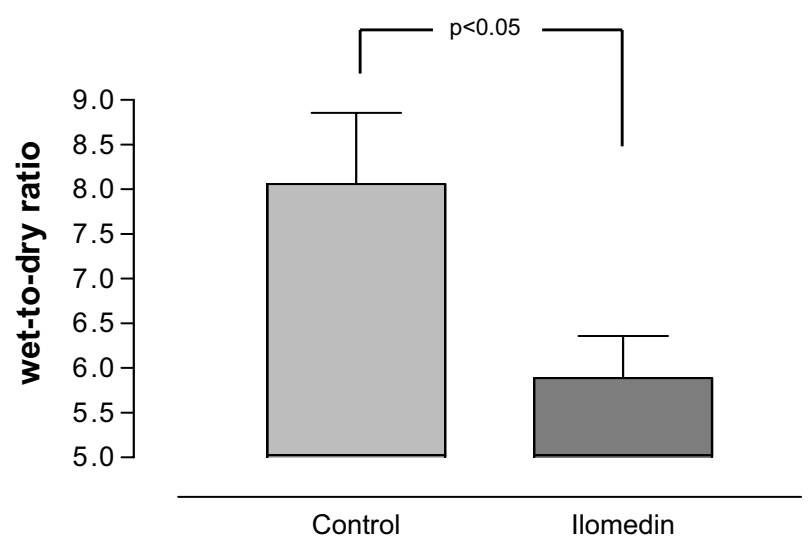

Figure 2. Wet/dry lung weight ratios in iloprost (llomedin) and control groups.

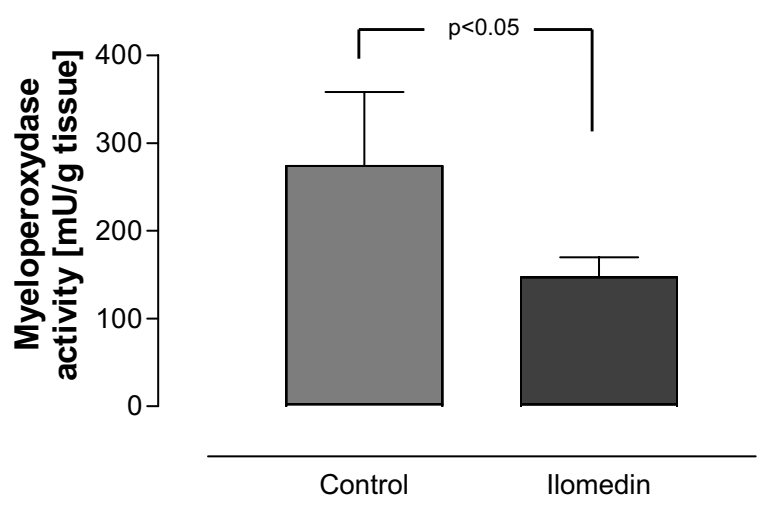

Figure 3. MPO activities in lung grafts in iloprost (llomedin) and control groups.

surfactant aggregate conversion, was observed. The SA/LAratio was lower in the iloprost group than in the control group, but the difference was not statistically significant $(P$ $=.08$ ). The protein content of the bronchoalveolar lavage fluid revealed a tendency towards higher values after reperfusion in both groups. However, this finding did not reach statistical significance $(P=.2)$.

\section{Discussion}

IR injury remains a significant problem in lung transplantation, leading to life-threatening graft dysfunction in approximately $10 \%$ to $20 \%$ of recipients after transplantation. ${ }^{1,21}$ Evidence from this study and from previous experiments by us and others suggests that prostanoids improve lung function when administered intravenously during the reperfusion period. ${ }^{14,15,22}$

We used a pig single-lung transplantation model of IR injury to evaluate the protective effects of iloprost as an additive to the lung preservation solution. We found that the addition of iloprost to the pulmonary flush solution (LPD) 


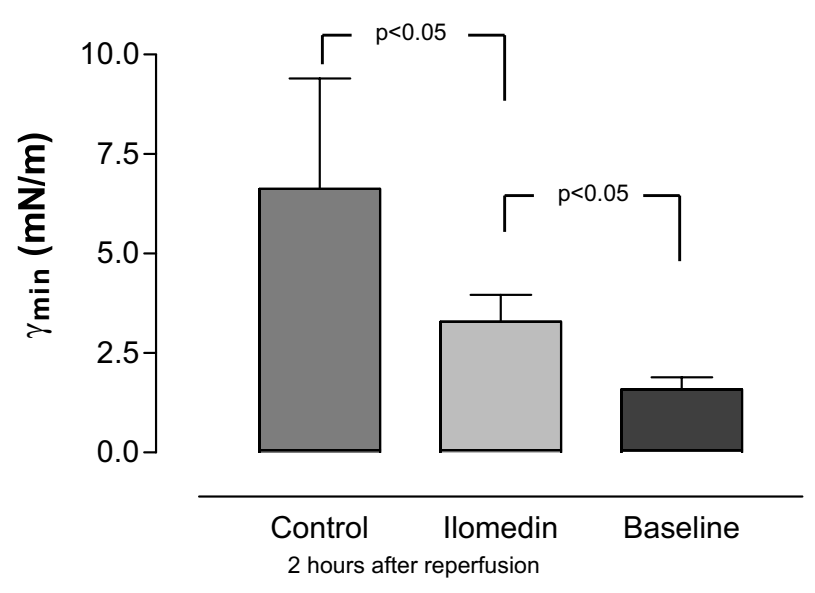

Figure 4. Surface tension $\left(\gamma_{\min }\right)$ in iloprost (llomedin) and control groups and in right donor lungs before retrieval (baseline).

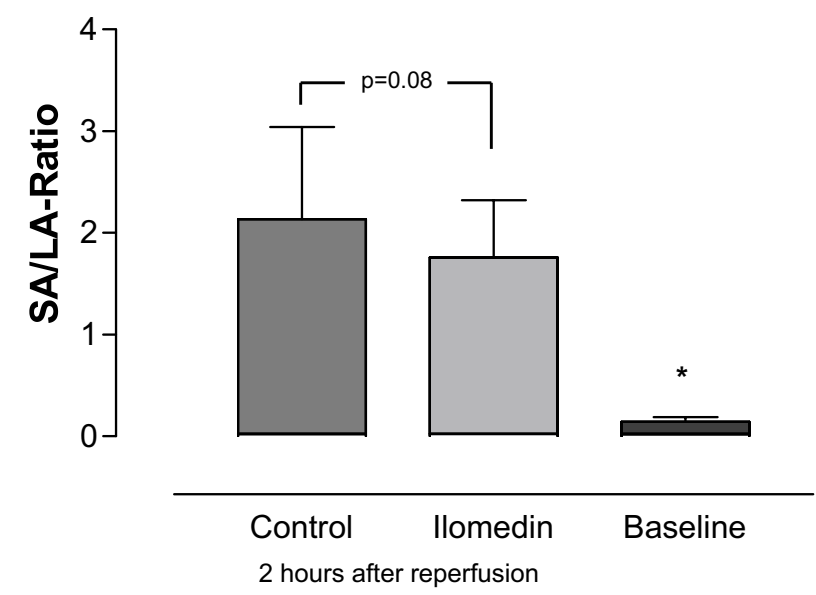

Figure 5. SA/LA ratio in iloprost (llomedin) and control groups 2 hours after reperfusion and in right donor lungs before graft retrieval (baseline). Asterisk indicates $\boldsymbol{P}<.05$ versus two study groups.

during cold ischemia resulted in improved posttransplantation oxygenation ability, decreased PVR and pulmonary arterial pressure, improved surfactant function, decreased postreperfusion lung graft edema, improved cardiac output, and decreased neutrophil sequestration in the graft during reperfusion and after 7 hours of reperfusion. This model has proved useful in our previous studies of interventions to protect against IR injury after lung transplantation. ${ }^{23} \mathrm{We}$ preserved the lungs for an extended period of 24 hours to ensure that we had sufficiently severely injured lungs. We chose to examine the severity of the IR injury 7 hours after the start of reperfusion because this corresponds to a time point in the clinical setting when we frequently see evidence of this injurious process.

The protective mechanisms of iloprost as an additive to the lung graft flush solution on IR injury, particularly on surfactant preservation and posttransplantation function, are unknown and have not been studied previously. However, Puskas and associates ${ }^{24}$ have speculated that a possible protective effect of $\mathrm{PGE}_{1}$ on posttransplantation lung function could be seen in a beneficial effect on surfactant metabolism. Indeed, in this study we observed a significant improvement of posttransplantation surfactant function in the iloprost group relative to the control lungs. The improved surfactant function is represented by reduced minimal alveolar surface tension and a trend toward lower SA/LA ratios. ${ }^{23,25,26}$ The prevention of surfactant dysfunction in our study was associated with decreased IR injury in the transplanted lungs, as assessed by standard physiologic parameters commonly used in studying IR lung injury, including PVR, pulmonary arterial pressure, CI, oxygenation index $\left(\mathrm{PaO}_{2} /\right.$ inspired oxygen fraction ratio), wet/dry lung tissue weight ratio, and lung compliance. ${ }^{6,14,23}$

The underlying mechanisms by which iloprost improves lung preservation, and consequently posttransplantation lung and surfactant functions, are not clear. We observed an increase of the SA/LA ratio in both groups after reperfusion, indicating an inactivation of surfactant, most likely by plasma proteins leaking into the alveolar space. However, other parameters of lung edema, such as wet/dry weight ratio, revealed a reduction of capillary leakage with iloprost. One therefore would expect a reduction in the SA/LA ratio with iloprost. In this study, however, such a significant reduction of surfactant inhibition could not be shown.

Another hypothesis regarding how iloprost might protect surfactant function is the protection of type II cells by reduction of an inflammatory response during the early phase of reperfusion. The observed reduction of the myeloperoxidase activity in lung tissue may support this hypothesis. This mechanism is of utmost importance, because its consequences are not limited to the early posttransplantation period but may also have impact on long-term graft function. Because it is known that surfactant function is improved in the follow-up of all recipients, one should focus on the prevention of type II cell injury during preservation and reperfusion.

We have previously shown that a significant number of lung graft cells undergo apoptosis during the very early phase after clinical lung transplantation, with most being type II cells. ${ }^{27}$ Surfactant function is associated with the degree of type II and endothelial cell integrity, as shown by Novick and colleagues. ${ }^{28}$ Because an antiapoptotic effect of prostanoids has been described, we quantified the amount of apoptosis and further examined the expression of the antiapoptotic gene $\mathrm{Bcl}-2$ in our previous study on the effect of $\mathrm{PGE}_{1}$ on posttransplantation rat lung function. ${ }^{14} \mathrm{We}$ were unable to show either a decrease of the number of apoptotic cells or a significant upregulation of $B c l-2$, but we found a significant shift from proinflammatory to anti-inflammatory 
cytokines in transplanted lungs in study animals that received PG intravenously during the 2-hour reperfusion period. This underlines that prostanoids and other agents increasing cAMP inhibit the production of several cytokines, such as interleukin (IL) 12, tumor necrosis factor $\alpha$, and IL- $1 \beta .^{29}$ The underlying mechanism seems to be the downregulation of the action of nuclear factor $\kappa \mathrm{B}$. In contrast to these cytokines, IL-10 gene transcription is regulated by the family of cAMP-responsive nuclear factors. ${ }^{30}$ Thus prostanoids may directly downregulate tumor necrosis factor $\alpha$ and IL-12 and upregulate IL-10 from inflammatory cells, such as macrophages and dendritic cells.

The lung collectin surfactant protein-A has both antiinflammatory and prophagocytic activities. Borron and coworkers ${ }^{31}$ have previously shown that surfactant protein-A inhibits the macrophage production of tumor necrosis factor $\alpha$ stimulated by the gram-negative bacterial component lipopolysaccharide. ${ }^{31}$ From these findings, one might speculate that improved lung preservation by iloprost leads to improved posttransplantation surfactant function as a result of preservation of the surfactant's own ability to inhibit the release of proinflammatory cytokines by alveolar macrophages in the transplanted lung. Iloprost could minimize the posttransplantation proinflammatory response and ultimately might influence the development of bronchiolitis obliterans. This promising pathway has not been studied yet and will be investigated in greater detail in our laboratory in the future.

In summary, iloprost in the flush solution in a pig singlelung transplantation model decreased the severity of IR injury, as demonstrated by a trend toward improvements in oxygenation, hemodynamics, and posttransplantation pulmonary edema. Further, the amelioration of IR injury was associated with improved surfactant preservation and posttransplantation function. We were unable to ascertain the mechanism responsible for the beneficial effects seen, but that was not the aim of this study. Our attention should turn toward the previously described shift from a proinflammatory to an anti-inflammatory response to iloprost in lung preservation and transplantation and its relationship to improved surfactant preservation on posttransplantation lung injury. Our ultimate goal is to be able to apply this simple modification of lung preservation solutions to the clinical setting to improve lung function after transplantation.

\section{References}

1. Haydock DA, Trulock EP, Kaiser LR, Knight SR, Pasque MK, Cooper JD. Management of dysfunction in the transplanted lung: experience with seven clinical cases. Washington University Lung Transplant Group. Ann Thorac Surg. 1992;53:635-41.

2. Qayumi AK, Nikbakht-Sangari M, Godin DV, English JC, Horley KJ, Keown PA, et al. The relationship of ischemia-reperfusion injury of transplanted lung and the up-regulation of major histocompatibility complex II on host peripheral lymphocytes. J Thorac Cardiovasc Surg. 1998;115:978-89.
3. Penfield JG, Wang Y, Li S, Kielar MA, Sicher SC, Jeyarajah DR, et al. Transplant surgery injury recruits recipient MHC class II-positive leukocytes into the kidney. Kidney Int. 1999;56:1759-69.

4. Crocetti JG, O'Brien OB, Furukawa S, Love M, Criner GJ. The impact of reperfusion injury on the long term development of obliterative bronchiolitis (OB) in lung transplantation. Am J Respir Crit Care Med. 2000;161:A507.

5. Hopkinson DN, Bharbra MS, Hooper TL. Pulmonary graft preservation: a worldwide survey of current clinical practice. J Heart Lung Transplant. 1998;17:525-31.

6. Keshavjee SH, Yamazaki F, Yokomise H, Cardoso PF, Mullen JB, Slutsky AS, et al. The role of dextran 40 and potassium in extended hypothermic lung preservation for transplantation. $J$ Thorac Cardiovasc Surg. 1992;103:314-25.

7. Steen S, Sjoberg T, Massa G, Ericsson L, Lindberg L. Safe pulmonary preservation for twelve hours with low-potassium dextran solution. Ann Thorac Surg. 1993;55:434-40.

8. Sundaresan S, Lima O, Date H, Matsumura A, Tsuji, Obo H, et al. Lung preservation with low-potassium dextran flush in a primate bilateral transplant model. Ann Thorac Surg. 1993;56:1129-35.

9. Fischer S, Matte-Martyn A, de Perrot M, Waddell TK, Sekine Y, Hutcheon M, et al. Low-potassium dextran preservation solution improves lung function after human lung transplantation. $J$ Thorac Cardiovasc Surg. 2001;121:594-6.

10. Struber M, Wilhelmi M, Harringer W, Niedermeyer J, Anssar M, Kunsebeck A, et al. Flush perfusion with low-potassium dextran solution improves early graft function in clinical lung transplantation. Eur J Cardiothorac Surg. 2001;19:190-4.

11. Mayer E, Puskas JD, Cardoso PF, Shi S, Slutsky AS, Patterson GA. Reliable eighteen-hour lung preservation at 4 degrees and 10 degrees $\mathrm{C}$ by pulmonary artery flush after high-dose prostaglandin E1 administration. J Thorac Cardiovasc Surg. 1992;103:1136-42.

12. Chiang CH, Wu K, Yu CP, Yan HC, Perng WC, Wu CP. Hypothermia and prostaglandin E1 produce synergistic attenuation of ischemia reperfusion injury. Am J Respir Crit Care Med. 1999;160:1319-23.

13. Naka Y, Roy DK, Liao H, Chowdhury NC, Michler RE, Oz MC, et al. cAMP-mediated vascular protection in an orthotopic rat lung transplantation model. Insights into the mechanism of action of prostaglandin E1 to improve lung preservation. Circ Res. 1996;79:773-83.

14. de Perrot M, Fischer S, Liu M, Jin R, Bai XH, Waddell TK, et al. Prostaglandin E1 protects lung transplants from ischemia-reperfusion injury: a shift from pro- to anti-inflammatory cytokines. Transplantation. 2001;15:1505-12.

15. DeCampos KN, Keshavjee SH, Liu M, Slutsky AS. Prevention of rapid reperfusion-induced lung injury with prostaglandin E1 during the initial period of reperfusion. $J$ Heart Lung Transplant. 1998; 17:1121-8.

16. Matsuzaki Y, Waddell TK, Puskas JD, Hirai T, Nakajima S, Slutsky AS, et al. Amelioration of post-ischemic lung reperfusion injury by prostaglandin E1. Am Rev Respir Dis. 1993;148:882-9.

17. Pfeiffer UJ, Wiesner-Euteneier AJ, Lichtwarck-Aschoff M, Blümel G. Less invasive monitoring of cardiac output measurements using femoral arterial thermodilution. Clin Intensive Care. 1994; 5(Suppl):2832.

18. Godje O, Peyerl M, Sehbauer T, Dewald O, Reichard B. Reproducibility of double indicator dilution measurements of intrathoracic blood volume compartments, extravascular lung water and liver function. Chest. 1998;113:1070-7.

19. Enhorning G. Pulsation bubble technique for evaluation pulmonary surfactant. J Appl Physiol. 1977;43:198-203.

20. Suzuki K, Ota H, Sasagawa S, Sakatani T, Fujikura T. Assay method for myeloperoxidase in human polymorphonuclear leukocytes. Anal Biochem. 1983;132:345-52.

21. Christie JD, Bavaria JE, Palevsky HI, Litzky L, Blumenthal NP, Kaiser LR, et al. Primary graft failure following lung transplantation. Chest. 1998;114:51-60.

22. Aoe M, Trachiotis GD, Okabayashi K, Manchester JK, Lowry OH, Cooper JD, et al. Administration of prostaglandin E1 after lung transplantation improves early graft survival. Ann Thorac Surg. 1994;58: 655-61. 
23. Strueber M, Hohlfeld JM, Kofidis T, Warnecke G, Niedermeier J, Sommer SP, et al. Surfactant function in lung transplantation after 24 hours of ischemia: advantage of retrograde flush perfusion for preservation. Eur J Cardiovasc Surg. 2002;123:98-103.

24. Puskas JD, Hirai T, Christie N, Mayer E, Slutsky AS, Patterson GA. Reliable 30-hour lung preservation by donor lung hyperinflation. J Thorac Cardiovasc Surg. 1992;104:1075-83.

25. Hohlfeld JM, Tiryaki E, Hamm H, Hoymann HG, Krug N, Haverich A, et al. Pulmonary surfactant activity is impaired in lung transplant recipients. Am J Respir Crit Care Med. 1998;158:706-12.

26. Hamm H, Kroegel C, Hohlfeld JM. Surfactant: a review of its functions and relevance in adult respiratory disorders. Respir Med. 1996; 90:251-70.

27. Fischer S, Cassivi SD, Xavier AM, Cardella JA, Cutz E, Edwards V, et al. Cell death in human lung transplantation: apoptosis induction in human lungs during ischemia and after transplantation. Ann Surg. 2000;231:424-31.

28. Novick RJ, Gehman KE, Ali IS, Lee J. Lung preservation: the importance of endothelial and alveolar type II cell integrity. Ann Thorac Surg. 1996;62:302-14.

29. Parry GC, Mackman N. Role of cyclic AMP response elementbinding protein in cyclic AMP inhibition of NF-kappaB-mediated transcription. J Immunol. 1997;159:5450-6.

30. Platzer C, Meisel C, Vogt K, Platzer M, Volk HD. Up-regulation of monocytic IL-10 by tumor necrosis factor- $\alpha$ and cAMP elevating drugs. Int Immunol. 1995;7:517-23.

31. Borron P, McIntosh JC, Korfhagen TR, Whitsett JA, Taylor J, Wright JR. Surfactant-associated protein A inhibits LPS-induced cytokine and nitric oxide production in vivo. Am J Physiol Lung Cell Mol Physiol. 2000;278:L840-7.

Access to The Journal of Thoracic and Cardiovascular Surgery Online is reserved for print subscribers!

Full-text access to The Journal of Thoracic and Cardiovascular Surgery Online is available for all print subscribers. To activate your individual online subscription, please visit The Journal of Thoracic and Cardiovascular Surgery Online, point your browser to http://www.mosby.com/jtcvs, follow the prompts to activate your online access, and follow the instructions. To activate your account, you will need your subscriber account number, which you can find on your mailing label (note: the number of digits in your subscriber account number varies from 6 to 10). See the example below in which the subscriber account number has been circled:

\section{Sample mailing label}

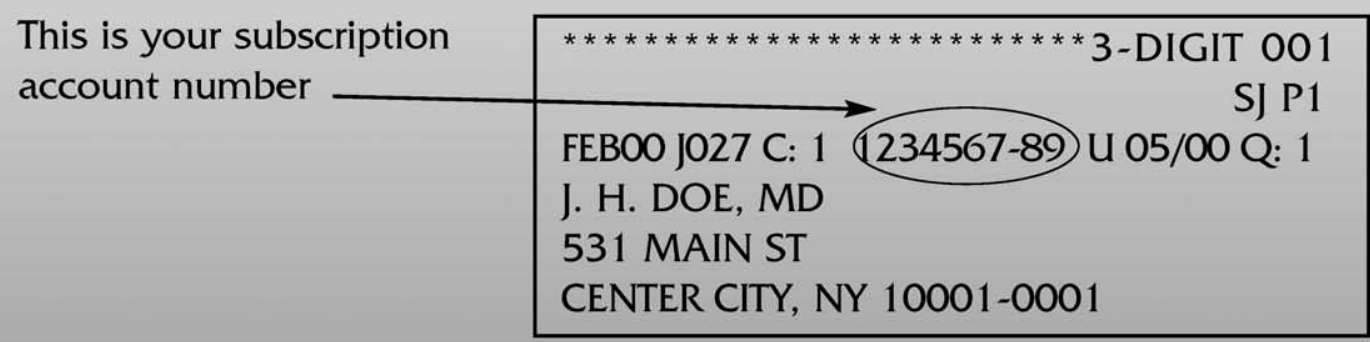

Personal subscriptions to The Journal of Thoracic and Cardiovascular Surgery Online are for individual use only and may not be transferred. Use of The Journal of Thoracic and Cardiovascular Surgery Online is subject to agreement to the terms and conditions as indicated online. 